\title{
Evidence of climate change using seasonal temperatures over Agege-Lagos. Nigeria
}

\author{
Emetere M.E. ${ }^{1.2^{*}}$, Afolalu S.A. ${ }^{3}$ and Peters U.J.. ${ }^{1}$ \\ ${ }^{1}$ Department of Physics. Covenant University Canaan land. P.M.B 1023. Ota. Nigeria. \\ ${ }^{2}$ Department of Mechanical Engineering Science. University of Johannesburg. South Africa. \\ ${ }^{3}$ Department of Mechanical Engineering. Covenant University Canaan land. Ota. Nigeria,
}

\begin{abstract}
Global change is evident as it affects the economy, health, agriculture, water supply, etc. The next generation may have stiffer experience if we do not mitigate anthropogenic pollution and plan for a safer environment. In this study, thirty-nine years temperature dataset from NASA was used to estimate the level of climate change in Agege, Lagos State of Nigeria. It was observed that climate change is evident over Agege, with $>80 \%$ each month showing slight and adverse anomalies. It is recommended that if fossil fuel and other anthropogenic emissions are reduced, and the government encourages renewable energy sources. Then, the significant influence of climate change on life basics can be mitigated for the future generation. With clear evidence of thermal anomalies, building professionals and town planners owe it a duty to enact thermal discomfort policies.
\end{abstract}

\section{Introduction}

Climate change can be referred to as the changes in the earth's climate structure that result in changes in the earth's weather patterns over a long period [1]. The earth is said to be warming if the energy coming in is greater than the energy going out but is considered cooling if the energy coming in is less than the energy going out. Climate changes affect the lives of plants, animals, and people alike. Climate change can occur over a short period that involves decades to over millions of years [2].

Climate change is regarded as one of the main problems of this century. It is a multidisciplinary problem that spans beyond atmospheric science to other geological features. [2-4]. Climate change in this modern day can be attributed to an increase in greenhouse gas emissions, which has caused an increase in atmospheric aerosols concentrations, thereby causing a warming effect [5-6]. The atmospheric aerosol concentrations can also result in a cooling effect. Climate change can occur due to environmental changes, such as deforestation, resulting in the reduction of oxygen emissions into the atmosphere [7]. In most parts of the world, woods are used for cooking, chimney, etc., thereby leading to more excellent greenhouse gas release within our environment. Also, fossil fuel burning increases greenhouse gases in the atmosphere. For example, the emission of $\mathrm{CO} 2$ has also been attributed to climate change [8-9]. CO2 is a greenhouse gas that is emitted in large amounts due to human operations.

Some scientists have postulated that climate change significantly influences the sicknesses, pandemics, and diseases, i.e., resulting in high mortality rates globally [10-11]. One of the evidences of climate change is an extreme weather event. For example, global warming and climate change have brought about the experience of hotter temperatures in some regions of the globe and colder seasons in some other regions of the globe. In some parts of northern Nigeria, the increase in temperature result to notable heat-related diseases such as meningitis, heat exhaustion, heat cramps, and heat stroke (also known as sunstroke). Another evidence is the polar ice melting of the arctic ice sea, resulting in a rise in sea level and dangers of flooding [12] and wildfire [13] in certain areas around the world. Also, incessant flooding can be seen in different parts of the world. For example, the cases of huge wildfire in parts of Europe (e.g. Venice) and Australia.

Climate change has been projected to negatively influence agriculture (due to drought, low rainfall, etc.) and the economy. Researchers believe that Indonesia is one of the world's countries that will have a significant impact on climate change, and they also have pressing concerns on how climate change will affect the economy, agriculture, and other sectors of Indonesia [14]. Researchers at the University of Stanford believe that climate change in the nearest future will result in the reduction of critical symbiotic fungi that aid in the growth of trees and other plant life [15]. In this study, the evidence of climate change in the Agege town in Lagos metropolis. Nigeria was considered. This study aims to enable building professionals, town planners, and the populace to understand the need to reduce anthropogenic pollutions.

\section{Methodology}

* Corresponding author: emetere@yahoo.com 
The geographical coordinates of Agege are $6^{\circ} 37^{\prime} 19^{\prime \prime}$ North. $3^{\circ} 19^{\prime} 33^{\prime \prime}$ East. It is a suburb and local government area in the Ikeja Division of Lagos State. Nigeria. The geographical map of Agege is shown in Figure 1. About seven decades ago, this settlement was initially an agro area. In 1954, it was made a Local Government Area but was merged to the state capital (i.e.,
Ikeja) in 1967. There had been migration persons into the area for various reasons. The emergence of Lagos as Nigeria's capital in 1991 made the settlement a comfortable place for a settlement based on its proximity to Ikeja.

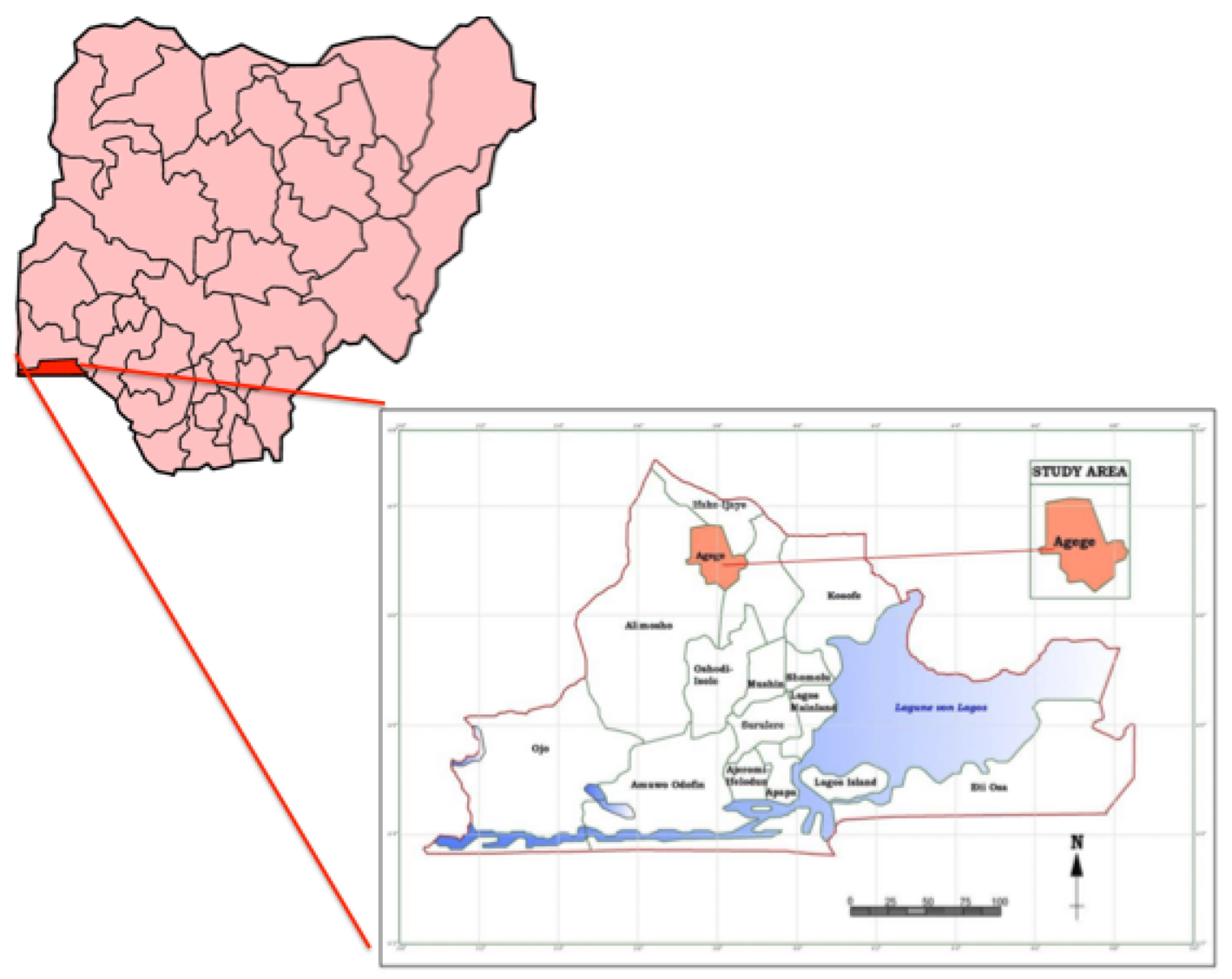

Fig.1. Geographical map of Agege

Agege is close to the largest dumpsite in Lagos (known as Olusosun dumpsite). The dumpsite receives approximately 40 percent of Lagos' total waste deposit, and its geographical size is 42.7 hectares. Refuse to burn, and all the likes are expected to influence warming in Agege. Hence, the temperature dataset was obtained at 2 $\mathrm{m}$ above ground using satellite remote sensing. Thirtynine years dataset (1980-2018) was obtained from the MERRA-NASA database for Agege. Lagos Nigeria. The primary two climatic seasons in Nigeria is the wet and dry seasons. In this research, the early dry season (i.e., September, October, November- SON). Late dry season (i.e., December. January February-DJF), early wet season (i.e., March. April. May - MAM) and late wet season (i.e., June. July. August-JJA) was considered.

\section{Results and Discussion}

Nigeria is characterized by two main seasons; dry and rainy seasons. In this research, the seasons were characterized into the early and late dry season. Also, the wet season was divided into the early and late wet season. In the dry season, Tropical Continental (cT) air mass flows in from the Sahara Desert. This time, dust wind is prevalent, and it is warm during the day and cooled in the night. So ideally, the early dry season supposes to be cooler than the late dry season.

On the other hand, air masses Tropical Maritime (mT) from the Atlantic Ocean controls the wet season. Usually, there is a rain break in the late wet season. Therefore, it is expected that the early wet season to be cooler than the late wet season, in analysing the thirty-nine years temperature dataset in Figures 2-5. This theory is used to determine if there are light or adverse climate changes in the area. There is light climate change if the only dry or wet season does not follow the established theories. The adverse climate change is when none of the seasons follow the theory that has been established. In the first decade, i.e., 1980 to 1989 (Figure 2), it was observed that the normal years was 1981 and 1982. The light climatic changes were observed in 1980 (normal at dry season), 1983 (normal at dry season), 1984 (normal at dry season), 
1985 (normal at dry season), 1986 (normal at dry season), 1987 (normal at dry season), 1988 (normal at wet season) and 1989 (normal at wet season).

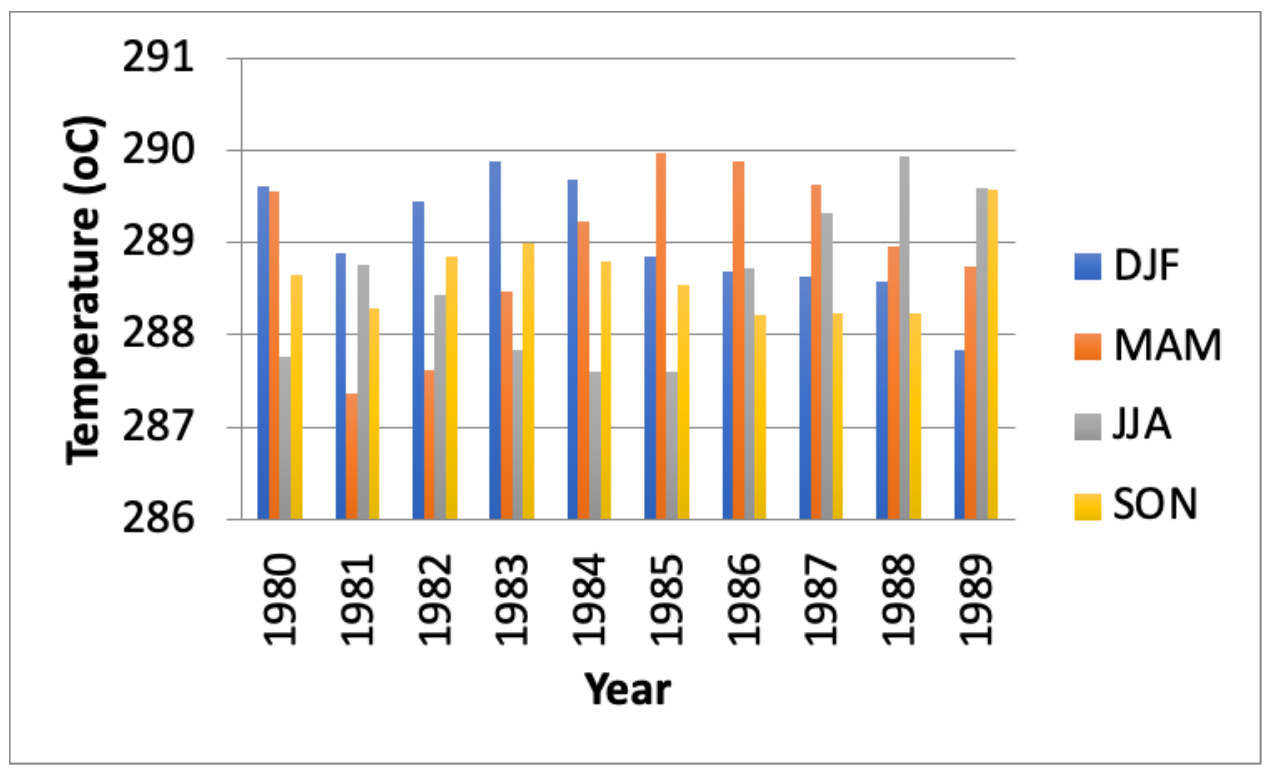

Fig.2. Seasonal temperature analysis between 1980-1989

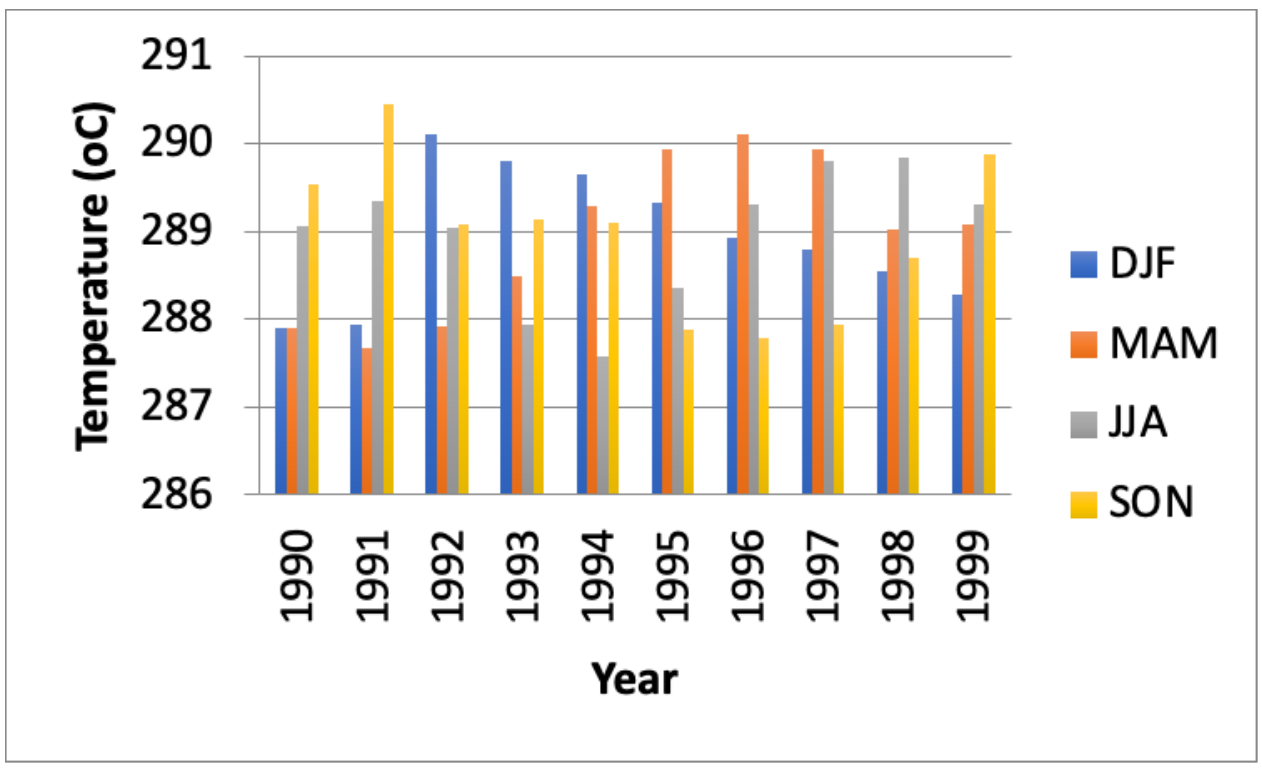

Fig.3. Seasonal temperature analysis between 1990-1999

Table 1. Statistical testing for climate change (1980-1999)

\begin{tabular}{|l|r|r|r|r|}
\hline & \multicolumn{1}{|l|}{$1980-1989$} & & \multicolumn{1}{|c|}{$1990-1999$} & \\
\hline Season & \multicolumn{1}{|c|}{ DRY } & \multicolumn{1}{|l|}{ WET } & \multicolumn{1}{l|}{ DRY } & \multicolumn{1}{l|}{ WET } \\
\hline Correlation & -0.0223 & -0.1483 & -0.3953 & 0.0134 \\
\hline Covariance & -0.0055 & -0.1037 & -0.2449 & 0.0083 \\
\hline F-test & 0.2721 & 0.8669 & 0.9522 & 0.6095 \\
\hline
\end{tabular}




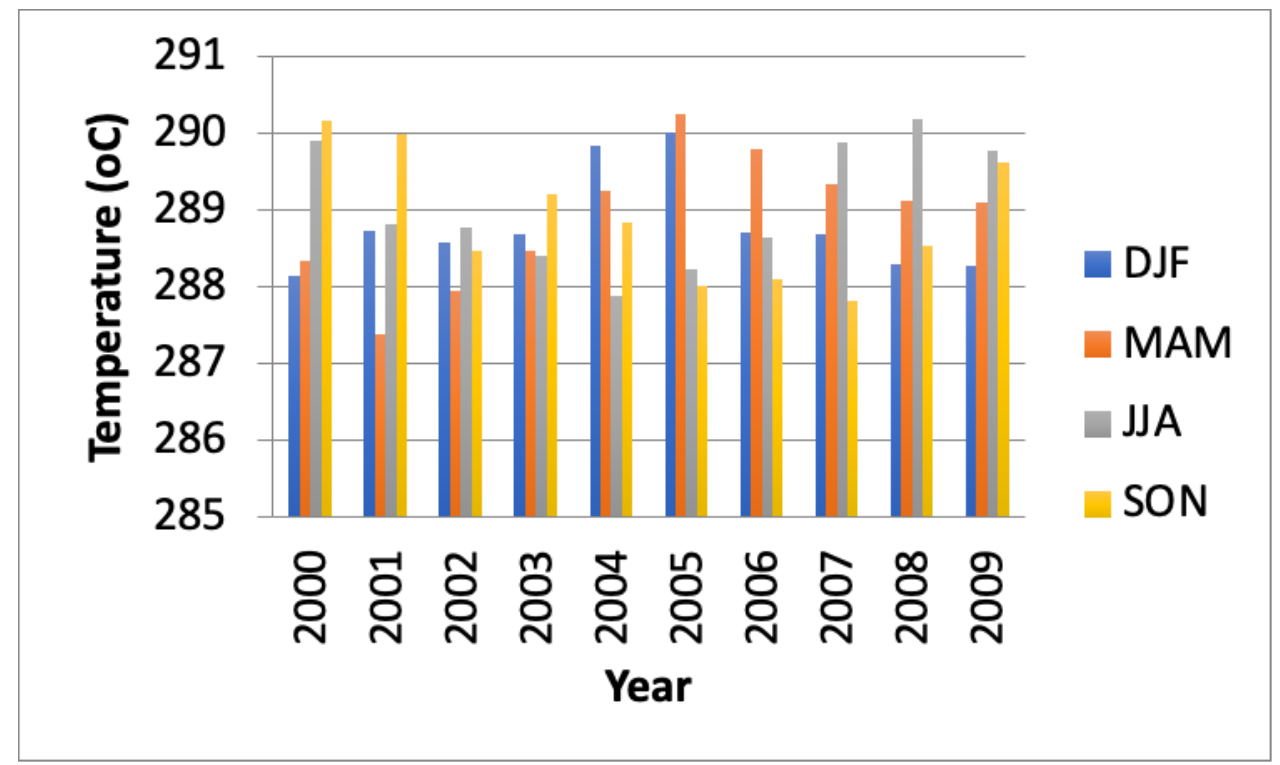

Fig.4. Seasonal temperature analysis between 2000-2009

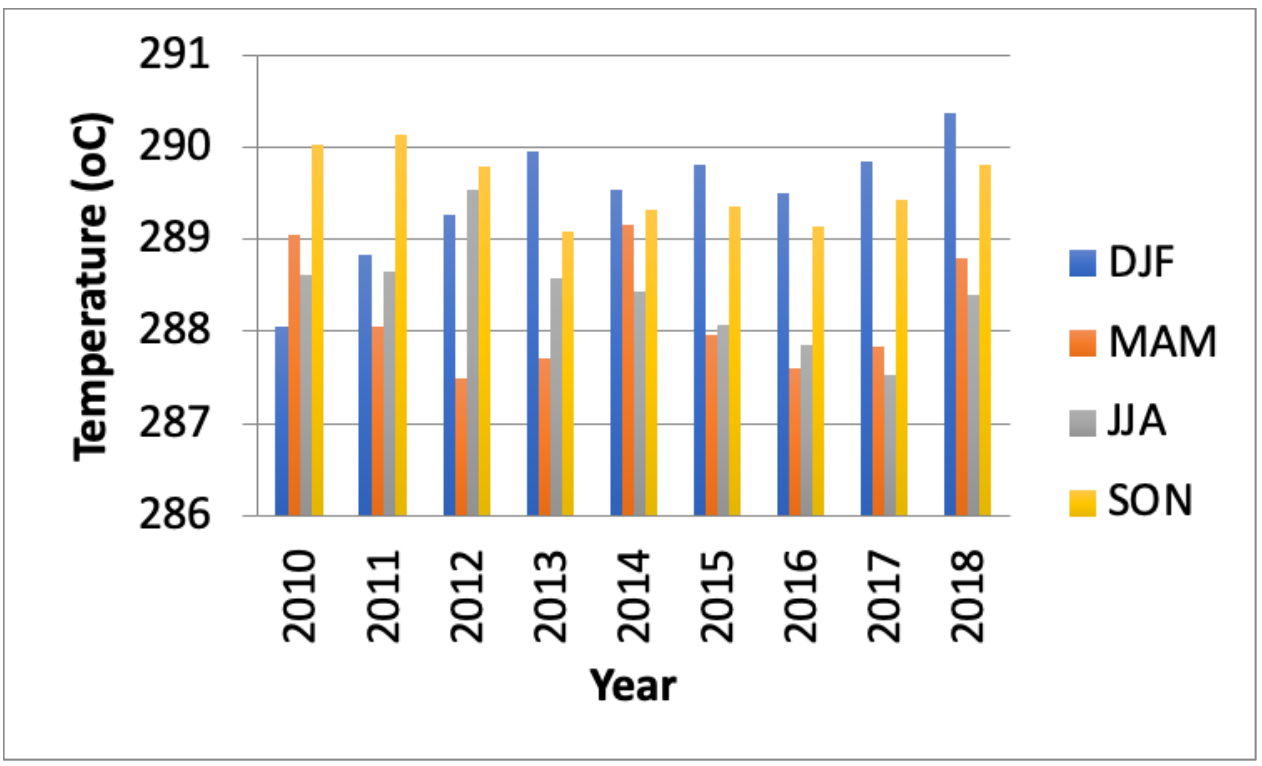

Fig.5. Seasonal temperature analysis between 2010-2018

Table 2. Statistical testing for climate change (2000-2018)

\begin{tabular}{|l|c|r|r|r|}
\hline & \multicolumn{1}{|c|}{$2000-2009$} & & \multicolumn{1}{c|}{$2010-2018$} & \\
\hline Season & DRY & WET & DRY & WET \\
\hline Correlation & $-0,41207$ & $-0,11341$ & $-0,58232$ & 0,00104 \\
\hline Covariance & $-0,19647$ & $-0,07183$ & $-0,13625$ & 0,00034 \\
\hline Ftest & 0,41115 & 0,86179 & 0,61208 & 0,74260 \\
\hline
\end{tabular}


In summary, there was no adverse climate change between 1980-1989. However, the light climatic changes were seen to shift from normal to dry season and then to the wet season. Correlation, covariance, and F-test reveal that there was no significance between the (early and late) wet and (early and late) dry seasons (Table 1). The F-test shows that there was less significance between the early and late wet season.

In the second decade, i.e., 1990-1999 (Figure 3), the normal year was 1992 and 1998. The years with slight climatic changes are 1990 (normal at wet season), 1991 (normal at wet season), 1993 (normal at dry season), 1995 (normal at dry season), 1996 (normal at dry season), 1997 (normal at dry season), 1999 (normal at wet season). The F-test shows more significance of less climate change in the dry season than the wet season (Table). In the third decade, i.e., 2000-2009 (Figure 4), the normal year was 2002 and 2007. The years with slight climatic changes are 2000 (normal at wet season), 2001 (normal at wet season), 2004 (normal at dry season), 2005 (normal at dry season), 2006 (normal at dry season), 2008 (normal at wet season), and 2009 (normal at wet season). The year with adverse climatic change was 2003 . The F-test shows that climate change was low for only the wet season. In the fourth decade, i.e., 2010-2018 (Figure 5), the years with an adverse climate change are 2010 and 2011. The normal years were 2013, 2015, and 2016. The years with slight climatic changes are 2011 (normal at wet season), 2012 (normal at wet season), 2017 (normal at dry season), and 2018 (normal at wet season). From the F-test, the wet and dry seasons showed less significance to climate change (Table 2).

\section{Conclusion}

This study shows that human influence plays a significant role in causing global warming today, and due to lack of action in reversing these influences, there will be increasing levels of climate change and warming and the increase in the severity of its effects in years to come. In other words, the alarming rate at which the climate crisis and global warming are accelerating the effects of these could be more dangerous than expected, and they could result in damages to the ecosystem. The following recommendation is made to curb the products of climate change: create awareness on the dangers of climate change and global warming to not just environments but people, animals, and plants alike; invest in renewable energy sources in our homes, business workplaces, and facilities to enter reduction in the release of toxic and harmful greenhouse gases into our atmosphere; invest in appliances that conserve energy; reduce the amount of wastewater to reduce pollution due to carbon oxide emission; invest in electric or non-fossil automobiles; boost governmental policies on the use of renewable energy sources..

\section{Acknowledgment}

The authors acknowledge the partial sponsorship of Covenant University.

\section{References}

1. IPCC. (1996). Climate Change, 1995. Impacts, Adaptation and Mitigation of Climate change 1995, Impacts, Adaptation and Mitigation of Climate change. Cambridge. Cambridge University Press. England. , $\ddot{A} \circledast$

2. Ayansanwo, T.O., 2003. Fisheries Development in Nigeria with Reference to Ogun State. Report submitted at TCDC International Training Center in Jiangsu (Wuxi city) China, pp: 1-30. ,Ä®

3. NEST (2011). Gender and climate change adaptation: Tools for community-level action in Nigeria. Ibadan, Nigeria: Nigerian Environmental Study/Action Team (NEST) - - BNRCC. https:/genderinsite.net/sites/default/files/BNRCCGender-Toolkit.pdf

4. Haines N, Korats RSD, Campbell- Lendrumb C, Corralan C. Climate change and human health: Impacts, vulnerability and public health. Journal of the Royal Institute of Public health. 2006;120:585. ,

5. Nkmedirim LC. (2003). Climates im transition: Commission on climatology. Washington DC, Minateman Press; , $\ddot{A} \AA$

6. Emetere M.E., (2018). Gaussian algorithm for retrieving and projecting aerosols optical depth: A case study of Monrovia-Liberia, The International Journal of Multiphysics 12 (3): 235-259

7. EPA (2020). Climate Impacts on Forests, https://19january2017snapshot.epa.gov/climateimpacts/climate-impacts-forests_.html (Accessed 30/04/2011)

8. Ritchie H, and Roser M, $2018 \mathrm{CO}$,ÇÇ and other Greenhouse Gas Emissions, Available on https://ourworldindata.org/

9. EPA report, 2014 Global Greenhouse Gas Emissions Data, United States Environmental Protection Agency, Available on https://www.epa.gov/

10. Wu X, Lu Y, Zhou S, Chen L, Xu B. (2016). Impact of climate change on human infectious diseases: empirical evidence and human adaptation. Environ. Int. 86:14-23

11. Chastonay P, Zybach U, Simos J, Mattig T. (2015). Climate change: an opportunity for health promotion practitioners?Int. J. Public Health 60:763-64

12. Melissa Denchak, (2019), Flooding and Climate Change: Everything You Need to Know, https://www.nrdc.org/stories/flooding-and-climatechange-everything-you-need-know

(Accessed 30/04/2020)

13. NAU (2020). Climate Change and Wildfire, https://www7.nau.edu/itep/main/tcc/docs/resources/o m_WildfireFactSheet_081512.pdf

(Accessed 30/04/2020) 
14. NRI (2020). Forests and Landscapes in Indonesia https://www.wri.org/our-work/project/forests-andlandscapes-indonesia/climate-change-indonesia

(Accessed 30/04/2020)

15. Taylor Kubota (2020). Stanford researchers study fungal diversity and its relationship to the future of forests, https://news.stanford.edu/2020/01/22/fungaldiversity-future-forests/ (Accessed 30/04/2020) 